\title{
Identification of ANAPC13 gene polymorphisms associated with body measurement traits in Bos taurus
}

\author{
B.J. Jiang ${ }^{1}$, X.L. Zhan ${ }^{1}$, C.Z. Fu ${ }^{1}$, H.B. Wang ${ }^{1,2}$, G. Cheng ${ }^{1,2}$ and L.S. Zan ${ }^{1,2}$ \\ ${ }^{1}$ College of Animal Science and Technology, Northwest A\&F University, \\ Yangling, Shaanxi, P.R. China \\ ${ }^{2}$ National Beef Cattle Improvement Center of Northwest A\&F University, \\ Yangling, Shaanxi, P.R. China \\ Corresponding author: L.S. Zan \\ E-mail: zanls@yahoo.com.cn
}

Genet. Mol. Res. 11 (3): 2862-2870 (2012)

Received January 30, 2012

Accepted May 24, 2012

Published June 15, 2012

DOI http://dx.doi.org/10.4238/2012.June.15.6

\begin{abstract}
Body measurement traits, influenced by genes and environmental factors, play numerous important roles in the value assessment of productivity and economy. There has been some indication that ANAPC13 influences adult height. We used PCR-SSCP and DNA sequencing technology to identify polymorphisms in the ANAPC13 gene. A polymorphism in intron $1(\mathrm{~A}>\mathrm{G}$ at base 17$)$ was identified and an additional polymorphic site $(\mathrm{C}>\mathrm{T}$ at base 42$)$ was also uncovered, which accompanied the previous polymorphism in more than $98 \%$ of the subjects. The two novel polymorphisms in exon 1 were assayed and potential associations with body measurement traits were evaluated in 404 individuals. Three genotypes were detected in the study group, named AACC, AGCT and GGTT. Significant differences were observed between genotypes AACC and AGCT for body length, withers height, hip height, hip width, heart girth, pin bone width. However, no associations were found among any genotypes and chest depth. We conclude that polymorphisms and mutations in non-coding regions of the ANAPC13
\end{abstract}


gene significantly affect body measurement traits.

Key words: ANAPC13; Body measurement traits; Cattle; PCR-SSCP; Polymorphism

\section{INTRODUCTION}

The identification of genetic markers that are positively associated with economically important traits in livestock species has the potential to significantly alter the rate of genetic improvement through the use of marker-assisted selection (MAS) (Nkrumah et al., 2003).

For many years, studies have attempted to identify genetic factors influencing human height so as to provide insights into human growth and development. Prior to 2007, genomewide linkage and candidate-gene association studies had limited success in this regard; however, with the recent emergence of genome wide association (GWA) studies, tens of common genetics variants influencing height have now been uncovered, primarily in adults (Weedon et al., 2007, 2008; Sanna, 2008; Gudbjartsson et al., 2008; Lettre et al., 2008; Soranzo et al., 2009). Although the causal variants at these loci are yet to be elucidated, it has been shown that many of the implicated genes are involved in pathways influencing bone and cartilage development, including skeletal development signaling (PTCH1, HHIP, BMPs, GDF5), the extra cellular matrix (ACAN, FBLN5, EFEMP1, ADAMTS17, ADAMTSL3), chromatin structure and regulation (DOT1L, SCMH1, HMGA2) and cell cycle regulation and mitosis (CDK6, ANAPC13, NCAPG) (Weedon and Frayling, 2008b). In addition, some of the loci were novel and are now a clear focus of attention in height biology. Such efforts are necessary, not only to provide novel biological insights, but also possibly to enable us to explain substantially more of the heritability of height (Weedon et al., 2008).

The role of cell cycle and mitosis-related genes have recently been highlighted by the identification of a gene for primordial dwarfism, a severe stature disorder in which patients present with an average adult height of only $100 \mathrm{~cm}$, various bone abnormalities and small brain size. Genes identified by monogenic studies will be excellent candidates for harboring the variants that explain normal variation in height (Weedon et al., 2008).

The APC/C first characterized as an E3 ligase specific for B-type cyclins, also appears to act on several mitotic kinases, mitotic spindle proteins and the DNA replication machinery (Peters, 2002; Harper et al., 2002). It is a cell cycle regulated ubiquitin ligase (Irniger et al., 1995; Sudakin et al., 1995), required for the ubiquitination of securin and cyclin-B (King et al., 1995; Aristarkhov et al., 1996). APC promotes metaphase/anaphase transition by the ubiquitination and degradation of securin, an inhibitor of separase that participates in the degradation of the sister chromatid cohesion complex. APC also ubiquitinates cyclin-B and accelerates its degradation during the late mitotic to the G1 phase, which leads to mitotic exit. Moreover, the mitotic spindle checkpoint is activated when APC activation is prevented, indicating that APC's dysregulation may result in chromosome instability (Tang et al., 2001). In addition, several APC-targeting molecules such as securin, polo-like kinase, aurora kinase, and SnoN have been reported to be oncogenes (Honda et al., 2000; Takai et al., 2001; Stroschein et al., 2001). Therefore, dysregulation of APC may be associated with tumorigenesis.

There is a growing consensus that the APC exists as a four-part enzyme with a structural complex, a catalytic arm containing the E2-binding sites, a tetratricopeptide repeat arm 
involved primarily in adaptor binding, and the adaptors that help promote the interaction with substrates, where this unit without the associated adaptors is known as the "APC core" (Thornton and Toczyski1, 2006).

In contrast to animals, plant development is mostly postembryonic; during embryogenesis the main developmental event is the establishment of the root-shoot axis. Organ initiation and growth take place after germination, driven by cell division and differentiation at the meristems. Ectopic expression of the Arabidopsis CDC27a, an APC subunit, accelerates plant growth (Rojas et al., 2009).

ANAPC13, also called APC13 or Swm1, is one of APC subunits and it may be involved in influencing adult height. Tremendous progress has been made towards understanding the regulation and function of $\mathrm{APC} / \mathrm{C}$ in the last decade. However, the information on vertebrate APC13 is quite limited. Based on the importance of ANAPC13 in adult stature morphogenesis and growth of the skeleton from determinations in human, it could be an attractive candidate gene for BMTs in cattle. Hence, the purpose of this study was to identify polymorphisms in the ANAPC13 gene with respect to association with BMTs. The knowledge of ANAPC13 gained in this study will contribute useful information for further research.

\section{MATERIAL AND METHODS}

\section{DNA samples and data collection}

Blood samples from 404 adult animals (24-30 months) were randomly selected from Qinchuan cattle breeding populations used to analyze the ANAPC13 allelic frequencies. The following traits were measured as previously described (Gilbert et al., 1993), including body length (BL), withers height (WH), hip height (HH), rump length (RL), hip width (HW), chest depth (CD), heart girth (HG), and pin bone width (PBW). In order to minimize systematic error, a single person was assigned to measure one of the eight traits in all animals.

Animals' blood samples were treated with $2 \%$ heparin and then stored at $-80^{\circ} \mathrm{C}$. DNA was extracted from blood samples according to standard procedures (Sambrook and Russell, 2002).

\section{PCR amplification and DNA sequencing}

According to the sequence of bovine ANAPC13 gene (GenBank accession No. NC_007299), one pair of primers (5'-CCTCGCCAAATGGACTCAC-3' and 5'-GAATGCCTTTTCCCCGCTA-3') was designed to amplify a 388-bp product of ANAPC13 in exon 1. PCR amplifications were performed in $20-\mu \mathrm{L}$ reaction mixture containing $50 \mathrm{ng}$ DNA, $10 \mathrm{pM}$ each primer, $0.20 \mathrm{mM}$ dNTPs, $2.5 \mathrm{mM} \mathrm{MgCl}{ }_{2}$ and $0.5 \mathrm{U}$ Taq DNA polymerase (TaKaRa, Dalian, China). The PCR protocol was $95^{\circ} \mathrm{C}$ for 5 min followed by 35 cycles of $95^{\circ} \mathrm{C}$ for $30 \mathrm{~s}, 56.5^{\circ} \mathrm{C}$ annealing for $30 \mathrm{~s}$, and $72^{\circ} \mathrm{C}$ for $30 \mathrm{~s}$, and a final extension at $72^{\circ} \mathrm{C}$ for 10 min. PCR products were electrophoresed on $1.5 \%$ agarose gels (containing $200 \mathrm{ng} / \mathrm{mL}$ ethidium bromide) using $1 \mathrm{X}$ TBE buffer ( $89 \mathrm{mM}$ Tris, $89 \mathrm{mM}$ boric acid, $2 \mathrm{mM} \mathrm{Na}_{2}$ EDTA).

\section{SSCP polymorphism and sequencing}

Aliquots of $5 \mu \mathrm{L}$ of the PCR products were mixed with $8 \mu \mathrm{L}$ denaturing solution (95\% 
formamide, $25 \mathrm{mM}$ EDTA, $0.025 \%$ xylene-cyanole and $0.025 \%$ bromophenol blue), heated for $10 \mathrm{~min}$ at $98^{\circ} \mathrm{C}$ and chilled on ice for $5 \mathrm{~min}$. Next, $16 \mu \mathrm{L}$ of this mixture were applied to a $12 \%$ polyacrylamide gel (29:1 acrylamide:bis), 14\% (v/v) glycerol, and 10X TBE buffer, Electrophoresis was carried out with $1 \mathrm{X}$ TBE buffer $(89 \mathrm{mM}$ Tris-borate, $2 \mathrm{mM}$ EDTA, $\mathrm{pH}$ 8.3 ) at $250 \mathrm{~V}$ for $30 \mathrm{~min}$ and $115 \mathrm{~V}$ for $14 \mathrm{~h}$ at room temperature. The gel was stained with $0.1 \%$ silver nitrate (Lan et al., 2007) and visualized with $2 \% \mathrm{NaOH}$ solution (containing $0.1 \%$ formaldehyde) according to Zhang et al. (2007).

The PCR products from different PCR-SSCP genotypes were purified with Axygen kits (BMI Fermentas) and sequenced in both directions in an ABI PRIZM 377 DNA sequencer (Perkin-Elmer). The sequence maps were analyzed with the Chromas software.

\section{Statistical analysis}

The following items, including genotypic frequencies, allelic frequencies, HardyWeinberg equilibriums, gene homozygosity $\left(H_{\mathrm{O}}\right)$, gene heterozygosity $\left(H_{\mathrm{E}}\right)$, effective allele numbers $\left(N_{\mathrm{E}}\right)$ and polymorphism information content (PIC) were statistically analyzed according to the previous approaches of Nei and Roychoudhury (1974) and Nei and Li (1979). The association between SNP marker genotypes of ANAPC13 gene and records of BMTs (BL, WH, HH, RL, HW, CD, HG, PBW) were analyzed by the SPSS software (version18.0) according to the following statistical linear Equation:

$$
Y i j k=\mu+G_{j}+A_{i}+E_{i j k}
$$

where Yijk is the observation for the BMTs, $\mu$ is the overall mean for each trait, $G_{j}$ is the genotype effect, $A_{i}$ is the fixed effect of age, and Eijk is the random error.

\section{RESULTS}

\section{Genetic polymorphism of the bovine ANAPC13 gene and the $\chi^{2}$ test}

A 388-bp product of the ANAPC13 gene was amplified and the different SSCP variants exhibited were sequenced. Sequence analysis revealed a $A>G$ mutation at position $17 \mathrm{bp}$ together with a C > T mutation at 42 bp (consensus sequence, Embank NC_007299), named $17 \mathrm{~A}>\mathrm{G}$ and $42 \mathrm{C}>\mathrm{T}$. Moreover, the two SNPs seemed to have a congruent relationship since the SSCP result showed three genotypes (Figure 1) on condition that just two SNPs existed. Here, it was hypothesized that some associations should exist between them. Considering that it was difficult to determine this by the SSCP or RFLP methods, we selected about 100 individuals and sequenced them directly. As expected, the two SNPs (Figure 2) were in linkage and the vast majority of them were in three genotypes except that a couple of them were discordant with the previously speculated results (data not shown). No RFLPs were detected in the PCR products, and thus, we adopted the PCR-SSCP method to sort out the rest of the experimental population.

The genetic diversity of the locus was then calculated (Table 1). Three kinds of genotypes were detected in the entire study group, namely AACC, AGCT and GGTT. The $\chi^{2}$ test showed 
that the genotype distributions were not in Hardy-Weinberg equilibrium $\left(\chi^{2}>\chi_{0.05}^{2}\right)$. AACC was the main genotype in all populations studied, while the frequency of the GGTT genotype in the total population was extremely low. According to the allele frequencies of the two SNPs, $H_{\mathrm{E}}, N_{\mathrm{E}}$ and PIC were $0.3055,1.4398$ and 0.2588 , respectively. Based on the classification of PIC (low polymorphism if PIC value $<0.25$, medium polymorphism if $0.25<$ PIC value $<0.5$, and high polymorphism if PIC value $>0.5$ ), the experimental population showed a medium polymorphism level.

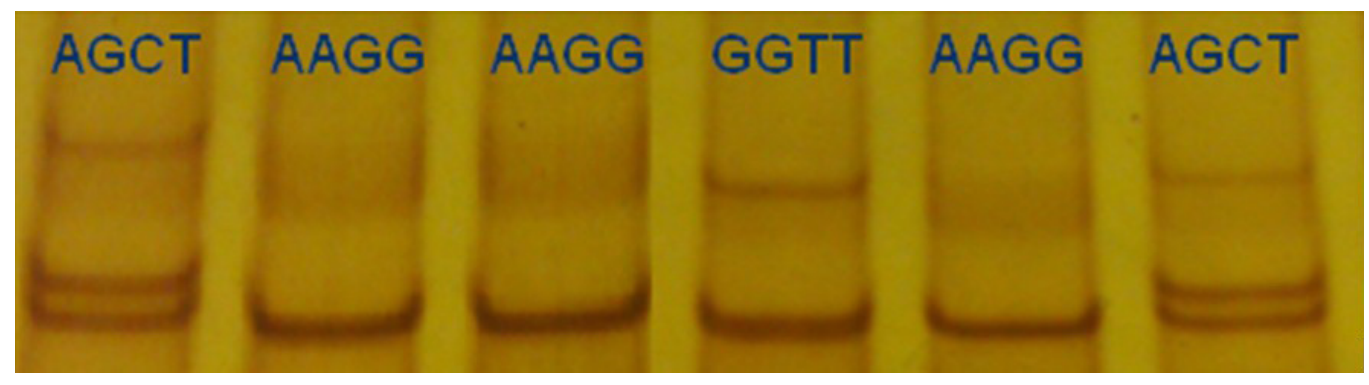

Figure 1. Electrophoresis patterns of PCR-SSCP exon 1 of the bovine ANAPC13 gene.

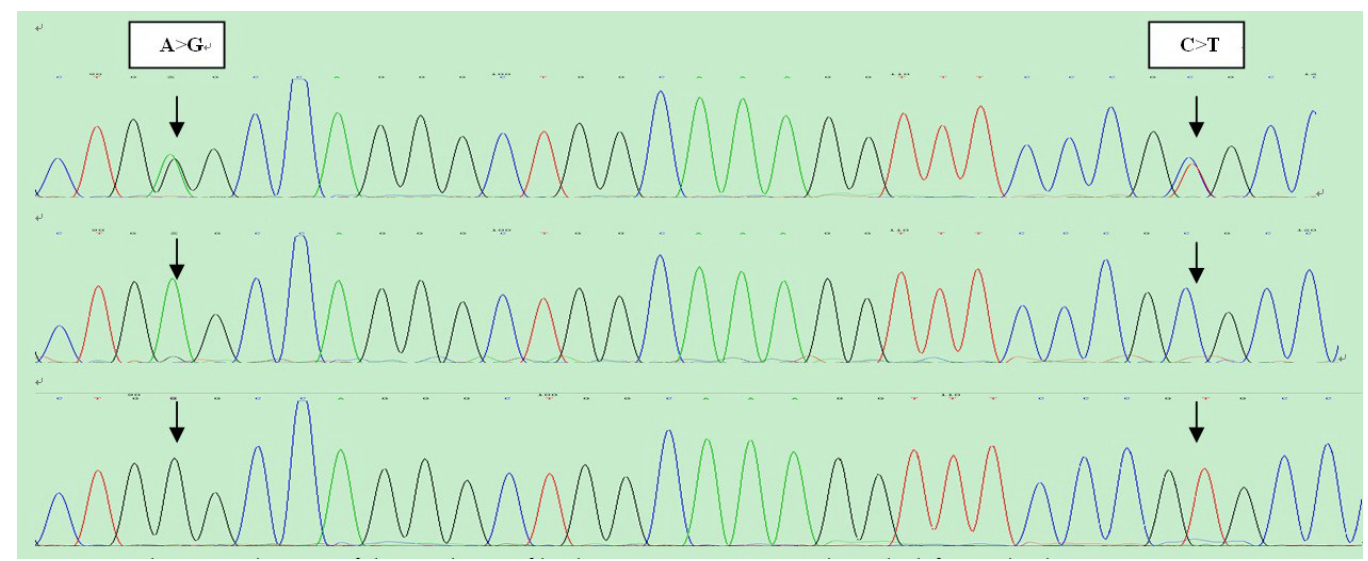

Figure 2. The sequencing map of the novel SNP of the bovine ANAPC13 exon 1 region. The left mutation is A> $\mathrm{G}$ and the right one is $\mathrm{C}>\mathrm{T}$.

Table 1. Genotype frequencies (\%) at the ANAPC13 gene for the SNP in Bos taurus populations.

\begin{tabular}{|c|c|c|c|c|c|c|c|}
\hline & \multicolumn{3}{|c|}{ Genotypic frequencies } & \multirow[t]{2}{*}{ Total } & \multicolumn{2}{|c|}{ Allelic frequencies } & \multirow{2}{*}{$\begin{array}{c}\chi^{2} \\
(\mathrm{HWE})\end{array}$} \\
\hline & AACC & AGCT & GGTT & & $\overline{\mathrm{A}(\mathrm{C})}$ & $\overline{G(T)}$ & \\
\hline Population & $0.6807(275)$ & $0.2624(106)$ & $0.0569(23)$ & 404 & 0.8119 & 0.1881 & 8.0372 \\
\hline
\end{tabular}

HWE $=$ Hardy-Weinberg equilibrium; $\chi 0.05^{2}=5.991, \chi 0.01^{2}=9.21$. 


\section{Effect of the polymorphism locus on BMTs}

Eight BMTs were analyzed by the comparison between the genotypes of 404 individuals and their phenotypic data. The results of association analysis are shown in Table 2. It was not hard to find that animals with the genotype AGCT had very significantly higher mean values compared to genotype AACC for the parameters $\mathrm{BL}$, WH, HH, HW, HG, and PBW (P < $0.01)$. Meanwhile, there were significant differences for $\mathrm{RL}(\mathrm{P}<0.05)$ between the two genotypes. However, no associations were found between any genotype and CD. Additionally, the frequency of GGTT genotype was exceedingly low in the experimental population together with no significant difference compared to genotype AGCT. A possible explanation for this observation is the occurrence of gene random drift due to the low frequency of alleles $\mathrm{G}$ and $\mathrm{T}$. Thus, we believe that the mutations for $17 \mathrm{~A}>\mathrm{G}$ and $42 \mathrm{C}>\mathrm{T}$ may have potential effects on BMTs in cattle and could be used for marker-assisted selection.

Table 2. Least square means and standard errors of the body measurement traits obtained for the genotypes of the ANAPC13 gene polymorphism in Qinchuan cattle.

\begin{tabular}{lccc}
\hline Traits $(\mathrm{cm}$, mean $\pm \mathrm{SE})$ & \multicolumn{3}{c}{ Genotypes } \\
\cline { 2 - 4 } & AACC & AGCT & GGTT \\
\hline Body length & $126.133 \pm 0.603^{\mathrm{A}}$ & $130.750 \pm 0.972^{\mathrm{B}}$ & $130.109 \pm 2.086^{\mathrm{AB}}$ \\
Withers height & $115.615 \pm 0.535^{\mathrm{A}}$ & $118.849 \pm 0.861^{\mathrm{B}}$ & $118.174 \pm 1.849^{\mathrm{AB}}$ \\
Hip height & $119.251 \pm 0.418^{\mathrm{A}}$ & $122.594 \pm 0.673^{\mathrm{B}}$ & $121.543 \pm 1.444^{\mathrm{AB}}$ \\
Rump length & $40.055 \pm 0.233^{\mathrm{a}}$ & $41.123 \pm 0.376^{\mathrm{b}}$ & $41.565 \pm 0.807^{\mathrm{ab}}$ \\
Hip width & $35.120 \pm 0.315^{\mathrm{A}}$ & $38.123 \pm 0.508^{\mathrm{B}}$ & $37.130 \pm 1.090^{\mathrm{AB}}$ \\
Chest depth & $57.375 \pm 1.732^{\mathrm{B}}$ & $57.566 \pm 2.790$ & $55.304 \pm 5.991$ \\
Heart girth & $152.065 \pm 0.971^{\mathrm{A}}$ & $161.604 \pm 1.565^{\mathrm{B}}$ & $155.435 \pm 3.359^{\mathrm{AB}}$ \\
Pin bone width & $16.800 \pm 0.195^{\mathrm{A}}$ & $18.717 \pm 0.314^{\mathrm{B}}$ & $18.217 \pm 0.675^{\mathrm{AB}}$ \\
\hline
\end{tabular}

a,b Means with different superscript letters are significantly different $(\mathrm{P}<0.05) .{ }^{\mathrm{A}, \mathrm{B}}$ Means with different superscript letters are significantly different $(\mathrm{P}<0.01)$.

\section{DISCUSSION}

Given that the BMTs are affected by many factors, such as genotype, sex, age, breed, herd, location, and other random environment factors, we established a new statistical model in which the three factors (breed, herd, and location) were involved and we then employed the least-squares method in GLM procedure of the SPSS18.0 software to do the related analysis (Liu et al., 2010).

Most SNPs of the bovine gene have been reported to be associated with BMTs in native Chinese cattle breeds by recent studies, including growth differentiation factor 5 (GDF5) gene, LIM homeobox 4 (LHX4) gene, PR domain containing the 16 (PRDM16) gene, gastrulation defective protein 1 (GAD1) gene, nucleotide binding protein nucleobindin 2 (NUCB2) gene, caprine somatostatin (SST), SST receptor 1 (SSTR1) gene, ghrelin precursor (GHRL) gene, and syndecan-1 (SDC1) gene (Mateescu et al., 2005; Liu et al., 2010; Ren et al., 2010; Wang et al., 2010; Li et al., 2010a,b; Jin et al., 2011; Sun et al., 2011).

Although some studies have focused on the association of ANAPC13 gene SNPs with human stature, there are no available data reported for cattle and other livestock. Therefore, based on these results of the genome-wide approach in humans and according to the conformity 
of the conservation of biological evolution in different organism, we applied the research results from the human ANAPC13 gene in analyzing polymorphism and genetic effects at the cattle ANAPC13 gene locus. Two polymorphisms were identified in this study, $17 \mathrm{~A}>\mathrm{G}$ and $42 \mathrm{C}>\mathrm{T}$; the data analysis showed some associations between the different genotypes and BMTs. The hybrid population showed higher values for $\mathrm{BL}, \mathrm{WH}, \mathrm{HH}, \mathrm{HW}, \mathrm{HG}$, and $\mathrm{PBW}(\mathrm{P}<0.01)$, without a corresponding increase in RL or HG, which is in accordance with the human data in some ways.

In accordance with this research, several other studies also reported significant associations with height, which are also consistent with the human data. They have identified a total of 44 independent variants that are robustly associated with adult height in the general population, using genome-wide association data. It is encouraging that many of the implicated genes are components of signaling pathways that are known to be important in skeletal growth and development (Weedon and Frayling, 2008). However, in contrast, one of the more notable results is the negative association with HMGA2. This gene is one of the loci most strongly associated with adult height, so its lack of association with childhood stature in a previous study is striking (Zhao et al., 2010). It should also be noted that animal growth is an ongoing process, where developmental factors may cloud detection at certain loci, including rapid growth stages, where nutrition plays a major role in growth and hormone signaling impacts at puberty. Therefore, our study may lack the power to detect stage-specific association when using a mixed age together with such a small experimental population. Still, the result may explain part of the genetic determination on BMTs of cattle at the molecular level.

In conclusion, we further investigated two significant SNPs by testing for association with BMTs. This is a basic step towards understanding the mechanisms accounting for polymorphisms of the ANAPC13 gene locus and their genetic effect in cattle BMTs. It will be interesting to explore, in further investigations, the mechanism and significance of the polymorphism to BMTs of cattle.

\section{ACKNOWLEDGMENTS}

Research supported by the National Twelfth "Five Year" Science and Technology Support Project (\#2011BAD28B04-03), the China National 863 Program (\#2011AA100307), GMO new varieties major project (\#2011ZX08007-002), the National Beef and Yak Industrial Technology System (\#CARS-38), the Program for Changjiang Scholars and Innovative Research Team (IRT0940), and the "13115" Scientific and Technological Innovation Program of Shaanxi Province (\#S2010ZDGC109). We thank all the investigators, research assistants and laboratory technicians who contributed to this study. We extend special thanks to Professor Zan, Dr. Wang and Dr. Cheng for their technical assistance.

\section{REFERENCES}

Aristarkhov A, Eytan E, Moghe A, Admon A, et al. (1996). E2-C, a cyclin-selective ubiquitin carrier protein required for the destruction of mitotic cyclins. Proc. Natl. Acad. Sci. U. S. A. 93: 4294-4299.

Gilbert RP, Bailey DR and Shannon NH (1993). Linear body measurements of cattle before and after 20 years of selection for postweaning gain when fed two different diets. J. Anim. Sci. 71: 1712-1720.

Gudbjartsson DF, Walters GB, Thorleifsson G, Stefansson H, et al. (2008). Many sequence variants affecting diversity of adult human height. Nat. Genet. 40: 609-615.

Harper JW, Burton JL and Solomon MJ (2002). The anaphase-promoting complex: it's not just for mitosis any more. Genes Dev. 16: 2179-2206. 
Honda K, Mihara H, Kato Y, Yamaguchi A, et al. (2000). Degradation of human Aurora2 protein kinase by the anaphasepromoting complex-ubiquitin-proteasome pathway. Oncogene 19: 2812-2819.

Irniger S, Piatti S, Michaelis C and Nasmyth K (1995). Genes involved in sister chromatid separation are needed for B-type cyclin proteolysis in budding yeast. Cell 81: 269-278.

Jin QJ, Sun JJ, Fang XT, Zhang CL, et al. (2011). Molecular characterization and polymorphisms of the caprine Somatostatin (SST) and SST Receptor 1 (SSTR1) genes that are linked with growth traits. Mol. Biol. Rep. 38: 3129-3135.

King RW, Peters JM, Tugendreich S, Rolfe M, et al. (1995). A 20S complex containing CDC27 and CDC16 catalyzes the mitosis-specific conjugation of ubiquitin to cyclin B. Cell 81: 279-288.

Lan XY, Pan CY, Chen H, Zhang CL, et al. (2007). An AluI PCR-RFLP detecting a silent allele at the goat POU1F1 locus and its association with production traits. Small Rumin. Res. 73: 8-12.

Lettre G, Jackson AU, Gieger C, Schumacher FR, et al. (2008). Identification of ten loci associated with height highlights new biological pathways in human growth. Nat. Genet. 40: 584-591.

Li F, Chen H, Lei CZ, Ren G, et al. (2010a). Novel SNPs of the bovine GAD1/gad67 gene and their association with growth traits in three native Chinese cattle breeds. Mol. Biol. Rep. 37: 501-505.

Li F, Chen H, Lei CZ, Ren G, et al. (2010b). Novel SNPs of the bovine NUCB2 gene and their association with growth traits in three native Chinese cattle breeds. Mol. Biol. Rep. 37: 541-546.

Liu YF, Zan LS, Li K, Zhao SP, et al. (2010). A novel polymorphism of GDF5 gene and its association with body measurement traits in Bos taurus and Bos indicus breeds. Mol. Biol. Rep. 37: 429-434.

Mateescu RG, Zhang Z, Tsai K, Phavaphutanon J, et al. (2005). Analysis of allele fidelity, polymorphic information content, and density of microsatellites in a genome-wide screening for hip dysplasia in a crossbreed pedigree. $J$. Hered. 96: 847-853.

Nei M and Roychoudhury AK (1974). Sampling variances of heterozygosity and genetic distance. Genetics 76: 379-390.

Nei M and Li WH (1979). Mathematical model for studying genetic variation in terms of restriction endonucleases. Proc. Natl. Acad. Sci. U. S. A. 76: 5269-5273.

Nkrumah JD, Li C, Basarab JB, Guercio S, et al. (2003). Association of a single nucleotide polymorphism in the bovine leptin gene with feed intake, feed efficiency, growth, feeding behaviour, carcass quality and body composition. Can. J. Anim. Sci. 84: 211-219.

Peters JM (2002). The anaphase-promoting complex: proteolysis in mitosis and beyond. Mol. Cell 9: 931-943.

Ren G, Chen H, Zhang LZ, Lan XY, et al. (2010). A coding SNP of LHX4 gene is associated with body weight and body length in bovine. Mol. Biol. Rep. 37: 417-422.

Rojas CA, Eloy NB, Lima MF, Rodrigues RL, et al. (2009). Overexpression of the Arabidopsis anaphase promoting complex subunit CDC27a increases growth rate and organ size. Plant Mol. Biol. 71: 307-318.

Sambrook J and Russell DW (2002). Molecular Cloning. A Laboratory Manual. 3rd edn. Science Press, Beijing.

Sanna S, Jackson AU, Nagaraja R, Willer CJ, et al. (2008). Common variants in the GDF5-UQCC region are associated with variation in human height. Nat. Genet. 40: 198-203.

Soranzo N, Rivadeneira F, Chinappen-Horsley U, Malkina I, et al. (2009). Meta-analysis of genome-wide scans for human adult stature identifies novel loci and associations with measures of skeletal frame size. PLoS Genet. 5: e1000445.

Stroschein SL, Bonni S, Wrana JL and Luo K (2001). Smad3 recruits the anaphase-promoting complex for ubiquitination and degradation of SnoN. Genes Dev. 15: 2822-2836.

Sudakin V, Ganoth D, Dahan A, Heller H, et al. (1995). The cyclosome, a large complex containing cyclin-selective ubiquitin ligase activity, targets cyclins for destruction at the end of mitosis. Mol. Biol. Cell 6: 185-197.

Sun J, Jin Q, Zhang C, Fang X, et al. (2011). Polymorphisms in the bovine ghrelin precursor (GHRL) and Syndecan-1 (SDC1) genes that are associated with growth traits in cattle. Mol. Biol. Rep. 38: 3153-3160.

Takai N, Miyazaki T, Fujisawa K, Nasu K, et al. (2001). Polo-like kinase (PLK) expression in endometrial carcinoma. Cancer Lett. 169: 41-49.

Tang Z, Bharadwaj R, Li B and Yu H (2001). Mad2-Independent inhibition of APCCdc20 by the mitotic checkpoint protein BubR1. Dev. Cell 1: 227-237.

Thornton BR and Toczyski DP (2006). Precise destruction: an emerging picture of the APC. Genes Dev. 20: 3069-3078.

Wang J, Li ZJ, Lan XY, Hua LS, et al. (2010). Two novel SNPs in the coding region of the bovine PRDM16 gene and its associations with growth traits. Mol. Biol. Rep. 37: 571-577.

Weedon MN and Frayling TM (2008). Reaching new heights: insights into the genetics of human stature. Trends Genet. 24: 595-603.

Weedon MN, Lettre G, Freathy RM, Lindgren CM, et al. (2007). A common variant of HMGA2 is associated with adult and childhood height in the general population. Nat. Genet. 39: 1245-1250.

Weedon MN, Lango H, Lindgren CM, Wallace C, et al. (2008). Genome-wide association analysis identifies 20 loci that influence adult height. Nat. Genet. 40: 575-583. 
Zhang C, Wang Y, Chen H, Lan X, et al. (2007). Enhance the efficiency of single-strand conformation polymorphism analysis by short polyacrylamide gel and modified silver staining. Anal. Biochem. 365: 286-287.

Zhao J, Li M, Bradfield JP, Zhang H, et al. (2010). The role of height-associated loci identified in genome wide association studies in the determination of pediatric stature. BMC Med. Genet. 11: 96. 